\title{
ABLE, an Innovative Transparent Exoskeleton for the Upper-Limb
}

\author{
P. Garrec, J.P. Friconneau, Y. Méasson, Y. Perrot
}

\author{
CEA, LIST, Service de Robotique Interactive \\ 18 route du Panorama, BP6, FONTENAY AUX ROSES, F- 92265 France \\ Phone : +33146548994 ; Fax : +33146548980 ; Email philippe.garrec@cea.fr
}

\begin{abstract}
This paper presents ABLE, an innovative exoskeleton for the upper limb currently under development at CEA-LIST Interactive Robotics Unit (Fig 1). Its distinctive high performance mechanical transmissions - screw and cable patented arrangement [9] - and its integrated architecture makes it the very first of its category. The first $\mathbf{4}$ axis model is described here but more complete models are already planned: a 7 axis model as well as portable versions. Its back-drivable, high efficiency, low inertia actuators provide a high capacity (around $40 \mathrm{~N}$ continuous effort at the hand) and allow hybrid force-position control without requiring any force sensor. Its first application is currently a research program in rehabilitation (BRAHMA project) and professional use is already in view. Assistance tasks for disabled persons (carrying a bottle) are also typical tasks to be performed by ABLE as well as intuitive telerobotics, haptic device for VR, and sport training, etc. Furthermore, its versatility and simple design allow industrial versions to become soon available.
\end{abstract}
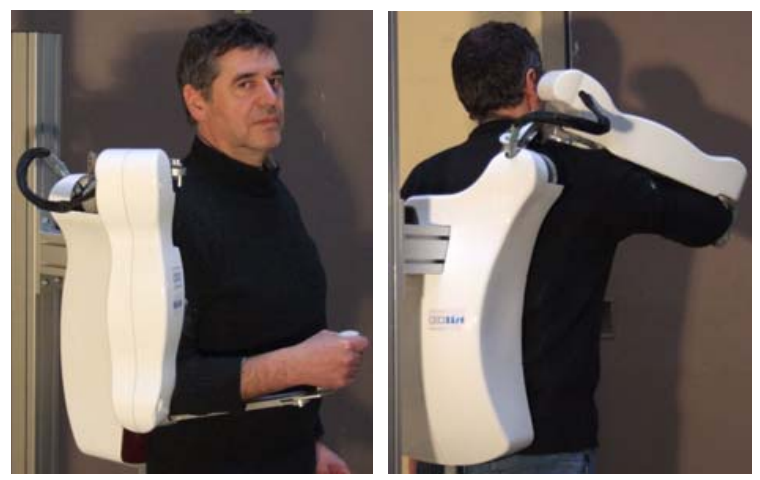

Fig 1. CEA-LIST 4 axis exoskeleton actuated by screw-and-cable actuators (SCS actuator)

\section{THE GENESIS OF ABLE - A SHORT STORY OF THE SCS ACTUATOR}

ABLE exoskeleton is directly related to electrical masterslave manipulator (EMSM) teleoperation technology in which our laboratory has played a historical role. Fig 2 shows a quick summary of well-known pioneering machines [8], [11], [12], [13], [14], [15], [16] illustrated with their mechanical solutions.
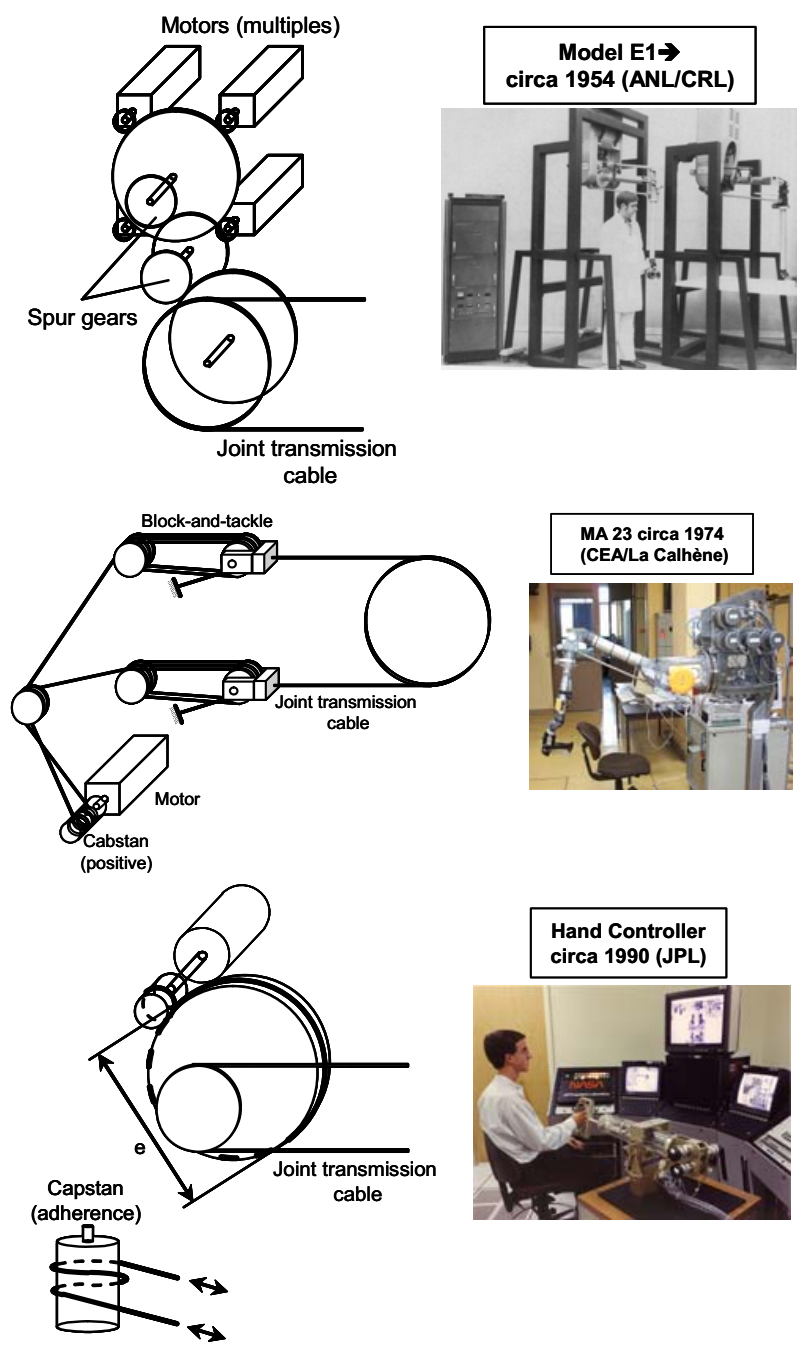

Fig 2. Landmarks in torque amplification for back-drivable electrical master-slave telemanipulator (EMSM)

The first principle has been used by R. Goertz (ANL) in his E1-E4 and Model M. Motor torque is amplified using high-precision spur gears driving the joints either directly (translation joints) or, like the scheme shows, trough transmission cable (for remote rotation joints). The second is due to J. Vertut and is team (CEA) for the MA 23. Motor 
torque is amplified using block-and-tackle cable (or tape) arrangements which drives a transmission cable (or tape). The last one, the capstan, is known to have been proposed for this function by J. K Salisbury (here the JPL Hand Controller). The cable is wrapped around pulleys to increase the adherence, thus enabling the capstan to transmit more torque with very low tension in the cable resulting in a very low friction threshold. For this reason, this is today the more sensitive device for torque amplification and it is most commonly used on haptic devices.

All of these machines have been mechanically designed to be back-drivable, highly efficient and have low friction threshold (no-load friction reflected on the limb), allowing force feedback without force sensor. This solution provides a high potential of reliability and availability. For example, the Mascot EMSM system [15] used by Oxford Technologies Ltd under the name DEXTER has performed over 7,500hrs of remote handling tasks inside the JET (Joint European Torus, UK) with a system availability above $95 \%$ in tough conditions. The central difficulty encountered by designers was to actuate the joints with a linear input-output torque law. All of these solutions - spur gears, block-andtackle, capstan - have a common drawback that has tended to limit their applications to a broader scale: The motor and the basic mechanism is transversal to the transmission cable making its integration in multi-axis serial manipulators rather difficult. As a consequence, the actuators are generally located at the base, resulting in complex routing and long cable loops for the last axis synonymous with more flexibility and friction.

In the late nineties we were working on the development of a new mechanical concept of transmission for highfidelity force feedback - the screw-and-cable transmission or SCS for Screw Cable System - to motorize a new master arm that could replace its predecessor - the MA 23 (CEA/La Calhène) [14] - in new force feedback teleoperation systems.

The first prototype (Fig 3) has been presented during the 9th American Nuclear Society Topical Meeting on Robotics and Remote Systems congress in Seattle in 2001 [6].

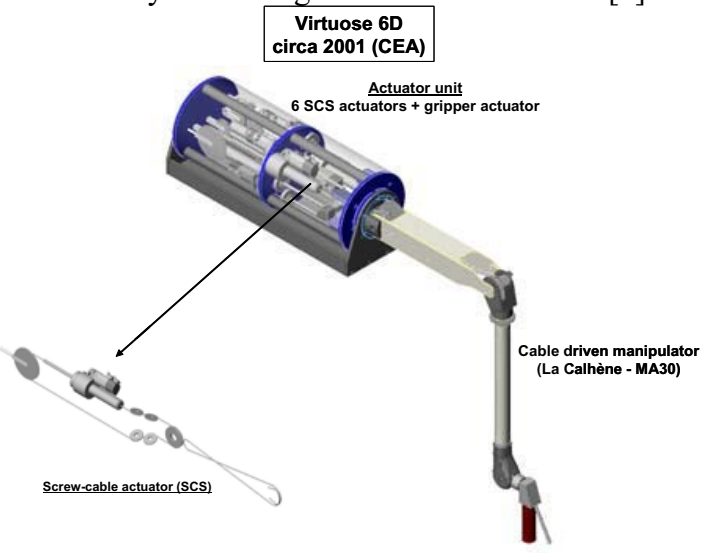

Fig 3. Virtuose $6 D$ the first six axis force feedback master arm powered by screws and cables
This master arm has been since industrialized and it is now commercialized by Haption ${ }^{\circledR}$ under the name Virtuose 6D 4040 (Fig 4) as a general purpose component for teleoperation (http://www.haption.com).

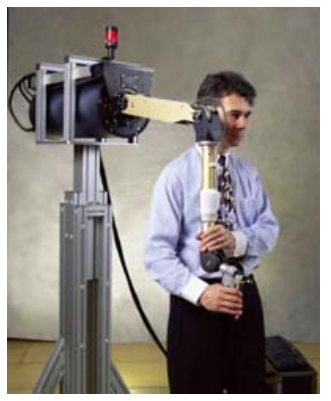

Fig 4. V6D 4040 an industrial version commercialized by Haption ${ }^{\circledR}$

The SCS actuator design has been presented in previous publications [3], [5], [6], [7], [8], [9] but it is important to summarize its basic principles here.
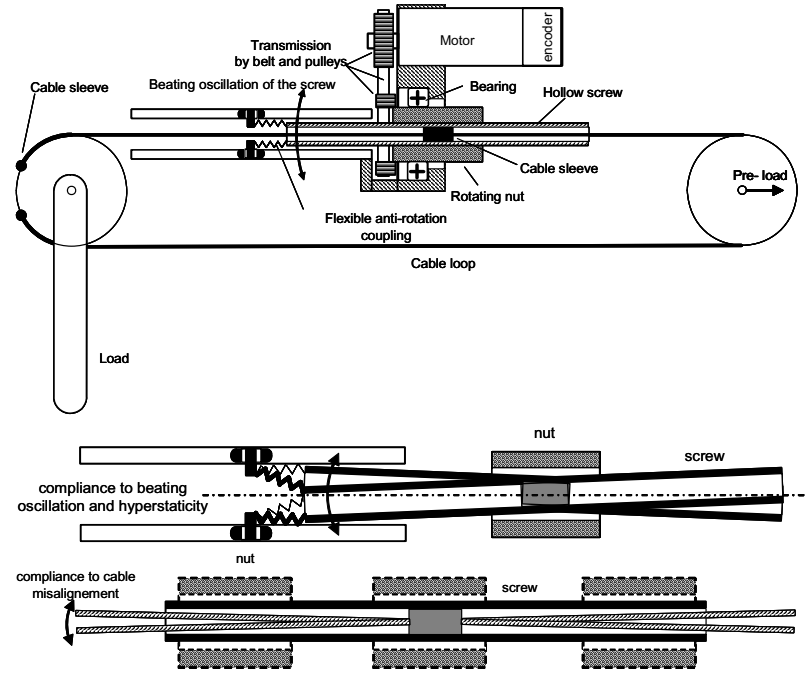

Fig 5. SCS basic principles

On the schemes (Fig 5) we can first see a general view of the actuator. A rotative joint is driven by a standard pushpull cable. On one side, the cable is driven by a ball-screw which translates directly in its nut (the screw is locked in rotation thanks to rollers moving into slots). The nut is rotating in a fixed bearing and is driven by the motor thanks to a belt transmission. Alternatively, a direct-drive pan-cake motor has been used in other applications as it is shown on Fig 6.

The particular patented mounting is detailed underneath. First of all, the ball-screw is free to oscillate thanks to a flexible coupling. These oscillations are known as beating oscillations and are amplified by the deliberate absence of centering device such as a linear bearing. Complementary the screw is bored and the cable passes inside with a radial play and is attached in its center. The scheme shows the various positions of the cable attachment relative to the nut when the screw is translated. This compliant mounting tends to isolate the screw from bending moments and thus 
guarantees a low and regular friction. The results is a highly linear force transmitter which is also unusually compliant to manufacturing imperfections and structural deformations.

As a summary, the main advantages of the SCS over previous solutions are:

- $\quad$ high force capacity (with ball-screws for instance)

- low friction threshold and high backdrivability allow force control without force sensor (reliability, absence of drift and calibration procedure, electromagnetic immunity, simplified wiring)

- motor aligned parallel to cable as opposed to any of the previous solutions in Fig 2: highly compact arrangement to actuate transversally compared to transversal motors or beveled gearboxes

- $\quad$ low inertia and high electrical stiffness

- $\quad$ high tolerance to manufacturing incertitude and to structure flexibility (wide choice of structural material)

- large section cable working at low speed/high force which is synonymous with endurance

Additionally cable transmission provides well-known advantages such us: shock absorption, smoothness, high efficiency, and design versatility for intricate routings through joints.

Shortly after completing Virtuose 6D, a specialized slave arm using SCS was also designed for radioactive waste retrieval (STeP: Système de Téléopération en Puits). This manipulator possesses 5 axis of which the first is a vertical translation and a gripper, all force controlled. We expanded upon the same mechanics but this time we opted for directdrive concentrical motors in order to pack its 6 actuators inside a half-cylinder housing which also integrates counterweights to compensate the actuator unit's weight on its vertical travel.

If for both Virtuose 6D and STeP the use of SCS led to a spectacular reduction of the mass and volume of their drive units - in comparison with let us say the well-known MA 23 (CEA-La Calhène) -, the manipulators themselves were commercially available cable-driven arm structures and the overall architecture of pioneering design was still present.
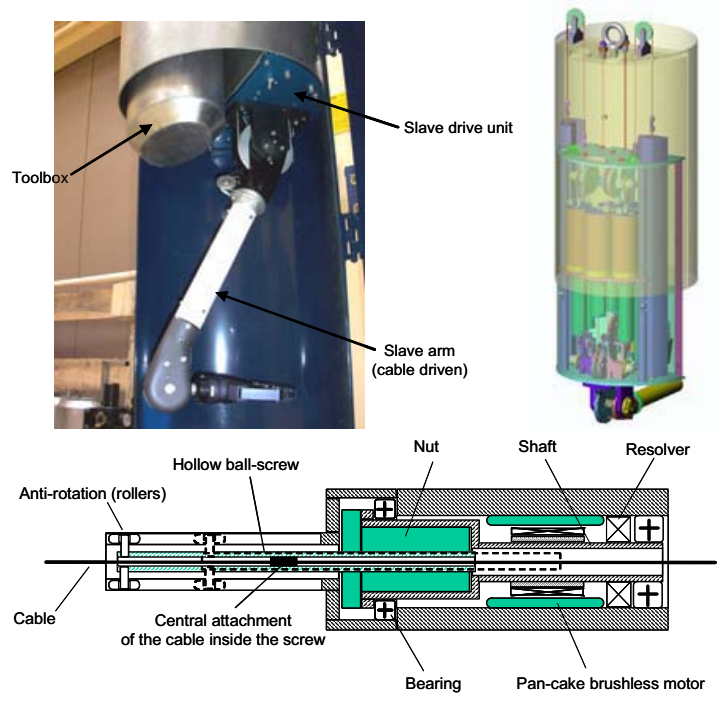

Fig 6. Top, STeP slave arm in a mock-up of a well (CEA-LIST) ; Bottom, Slave drive unit with direct-drive SCS

We soon realized that the SCS concept was not here fully exploited. It was then decided to work on their integration in the moving parts of the arm to offer a new deal to actuate a manipulator and the design of an exoskeleton for the upper limb quickly appeared to be the highest and most exciting challenge due to its broad potential of application.

\section{ABLE EXOSKELETON DESIGN}

In order to limitate the detrimental effect of an increased moving mass (weight and inertia) due to the integration of the SCS in the limb, it was decided to position the motor close to the upstream articulation of the arm using lightweight shafts to transmit the torque. At the same time, the transmission cable was shortened thus increasing its stiffness and leading to a satisfactory tradeoff (Fig 7).

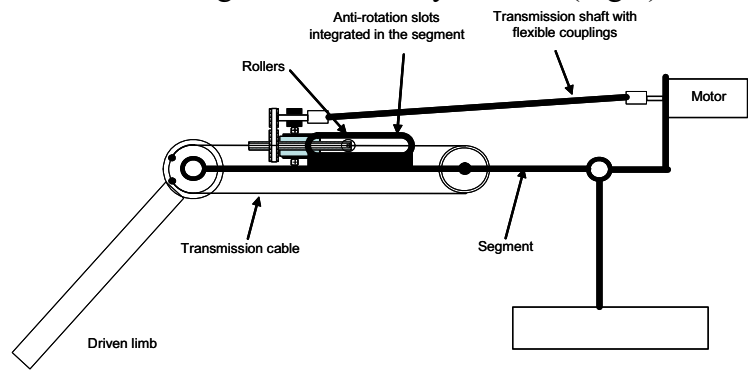

Fig 7. Embedded SCS principle

The second option was to take advantage of the flexibility of the cable to pack two SCS's in the arm module, each of them actuating a transversal axis (shoulder and elbow joint). The overall result is a streamline arm module where the two SCS's perform alike electrical muscles (Fig 8). 


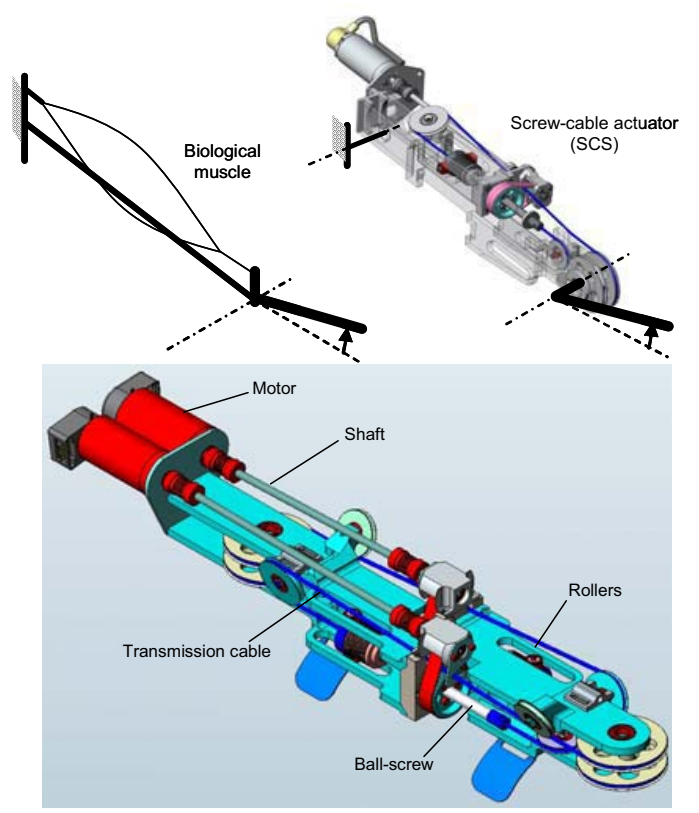

Fig 8. Arm module twin actuators and its analogy with biological muscles

In a second phase we designed the shoulder joint and the back module. The scheme Fig 9 shows the resulting kinematics of the 4 first joints. The shoulder articulation is a spherical articulation made of three orthogonal pivots whose common intersection approximately coincides with the center of the person's shoulder.

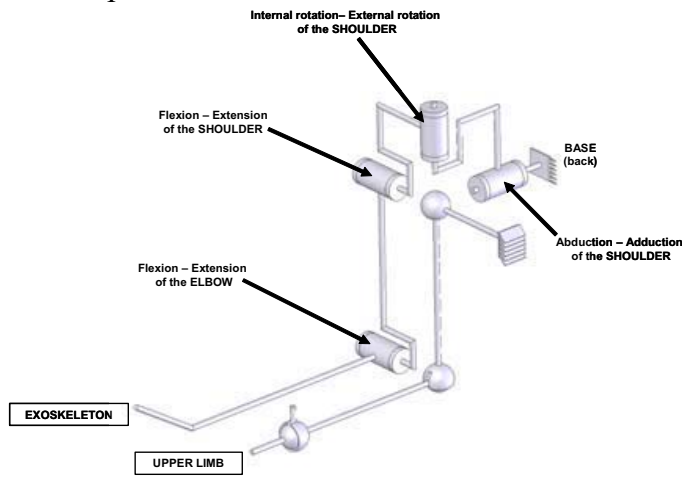

Fig 9. ABLE - 4 axis kinematics

However, the major difference with previous designs [1], [2], [4], [10] is that the second joint is realized with a circular guide. Such an arrangement is both free of singularity and not invasive as shown on Fig 10.

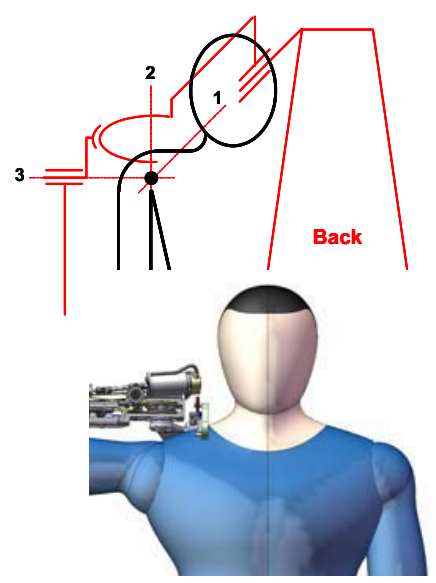

Fig 10. ABLE - 4 axis shoulder kinematics

The back module incorporates two SCS which drive the first and second joints whereas the third joint is driven transversally by one of the two embedded SCS of the arm module (Fig 11). The coupling effect between the two first joints is classically compensated by the control.
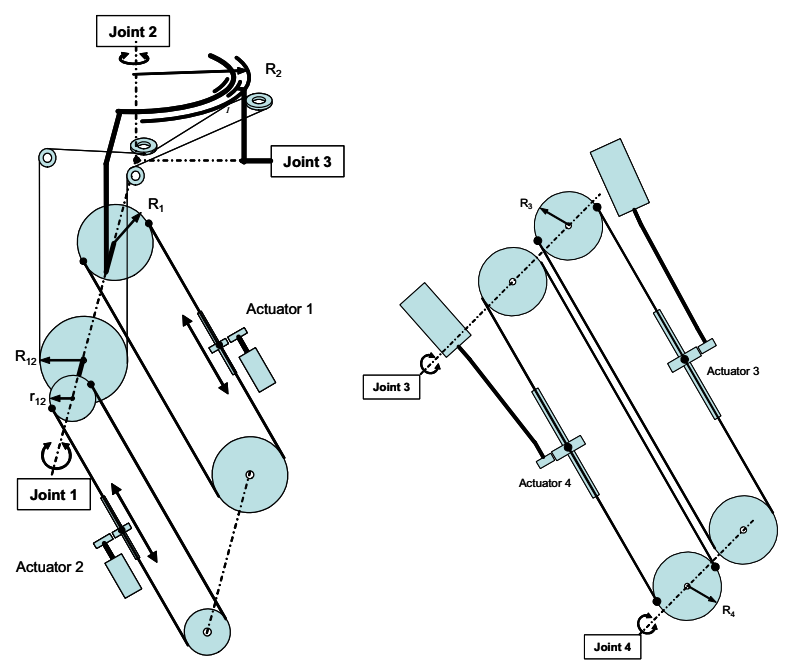

Fig 11. ABLE - 4 axis actuator kinematics: left, back module (Joints 1\&2); right, arm module (Joints $3 \& 4$ )

The result is a simple, integrated and morphologically compatible design combined with a distributed actuator mass and volume along the structure (Fig 12). 


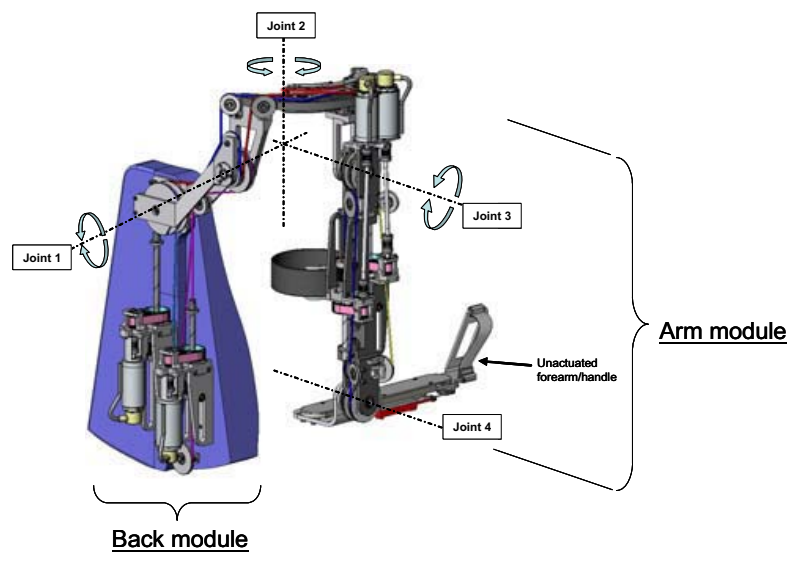

Fig 12. ABLE - 4 axis architecture

It is important to note that since the two SCS only occupy the half of the back module, it is possible to integrate the motorization of a second exoskeleton without any change of its volume.

The table below summarizes the basic specifications of ABLE - 4 axis.

TABLE I

ABLE - 4Axis Specifications

\begin{tabular}{|c|c|c|c|c|}
\hline \multirow{3}{*}{ JOINT } & Axis 1 & Axis 2 & Axis 3 & Axis 4 \\
\hline & Abduction / Adduction & Rotation Internal / External & Flexion / Extension & Flexion / Extension \\
\hline & \multicolumn{3}{|c|}{ SHOULDER } & ELBOW \\
\hline Amplitude & \multicolumn{3}{|c|}{$110^{\circ}$} & $130^{\circ}$ \\
\hline Motors & \multicolumn{4}{|c|}{ DC Faulhaber type } \\
\hline Transmission & \multicolumn{4}{|c|}{ Ball-screw and cable (SCS) } \\
\hline Speed (cartesian) & \multicolumn{4}{|c|}{$>1 \mathrm{~m} / \mathrm{s}$} \\
\hline $\begin{array}{l}\text { Joint torque } \\
\text { (continuous) }\end{array}$ & $18 \mathrm{Nm}$ & $18 \mathrm{Nm}$ & $13 \mathrm{Nm}$ & $13 \mathrm{Nm}$ \\
\hline $\begin{array}{c}\begin{array}{c}\text { Continuous effort in } \\
\text { hand }\end{array} \\
\end{array}$ & $50 \mathrm{~N}$ & $50 \mathrm{~N}$ & $40 \mathrm{~N}$ & $40 \mathrm{~N}$ \\
\hline \begin{tabular}{|c|}
$\begin{array}{c}\text { No-load friction in } \\
\text { hand (approx.) }\end{array}$ \\
\end{tabular} & \multicolumn{2}{|r|}{$3 \mathrm{~N}$} & \multicolumn{2}{|c|}{$2 \mathrm{~N}$} \\
\hline Mass (approx.) & \multicolumn{2}{|r|}{$3,0 \mathrm{~kg}$} & \multicolumn{2}{|c|}{$10,0 \mathrm{~kg}$} \\
\hline
\end{tabular}

\section{MODELING AND CONTROL}

The basic force feedback control principle is the same as with a conventional master arm (master-slave mode or haptic device). The torque of the motor is a combination of gravity compensation torque and a reaction torque proportional to a position error signal. The difference between the awaited position and the measured position is a result from output force exerted (by the operator or by a contact with an object). The proportionality between the position error and the exerted force is directly dependant upon the amount of friction in the transmission as shown on the diagram of Fig 13. At low speed (quasi-static condition), in absence of contact/reaction force the system is moved with a residual effort given by the " $y$ " distance between the $\mathrm{red} / \mathrm{blue}$ point and the black point.

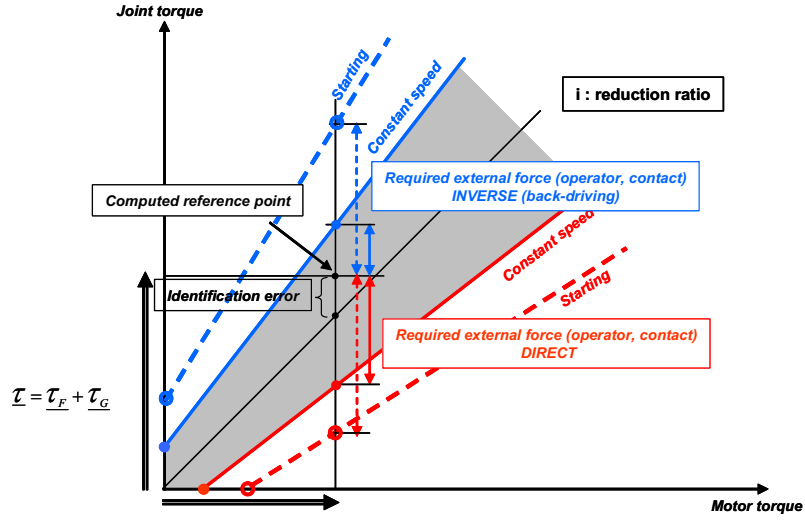

Fig 13. Actuator input-ouput force transmission diagram (in a quasi-static state)

No-load frictions (thresholds) are represented by the dots on " $x$ " and " $y$ " axis. The Direct (red) and Inverse (blue) characteristics correspond to respectively a motor state and a regenerative state (backdriving state). A highly linear transmission requires both a low threshold (compared to the maximum load capacity) and a high efficiency which means that both red and blue slopes should be close to the theoretical one (in black).

An input-output force transmission diagram (Fig 14) has been recorded for a typical SCS design with a THK BNK 1010 ball-screw.

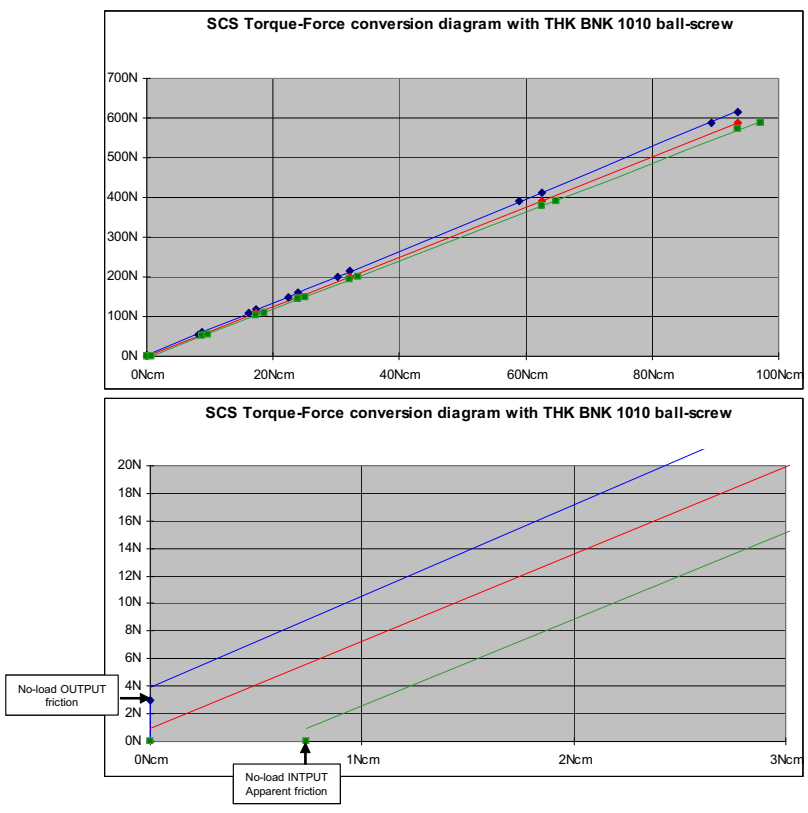

Fig 14. A typical SCS force transmission diagram

The maximum efficiency reaches approximately 0,94 in both sense and no-load friction represents approximately $1 / 1000$ of the maximum load capacity of the screw. These values show that in terms of force transmission quality, a SCS can compete with the best existing transmissions. 


\section{CONCLUSION}

The 4 axis version of ABLE exoskeleton is currently being used for the benefit of the BRAHMA project (rehabilitation). Not surprisingly, the first feedback from users indicates that design changes must be made to provide adjustments of the arm length. Progress must also be made to come up with smaller versions and widen the populations of users. In parallel, theoretical work is carried out to accurately model transmitted forces so that ultimately the exoskeleton could be used as a force/torque measurement device.

Regarding new developments, our objective is to soon realize a lightweight, 3 axis open forearm-wrist, fully actuated with ball-screws thus keeping the same level of transparency. This will lead to an anthropomorphic, fully open, ABLE - 7 axis model in 2009 allowing applications in teleoperation and Virtual Reality (Fig 15).

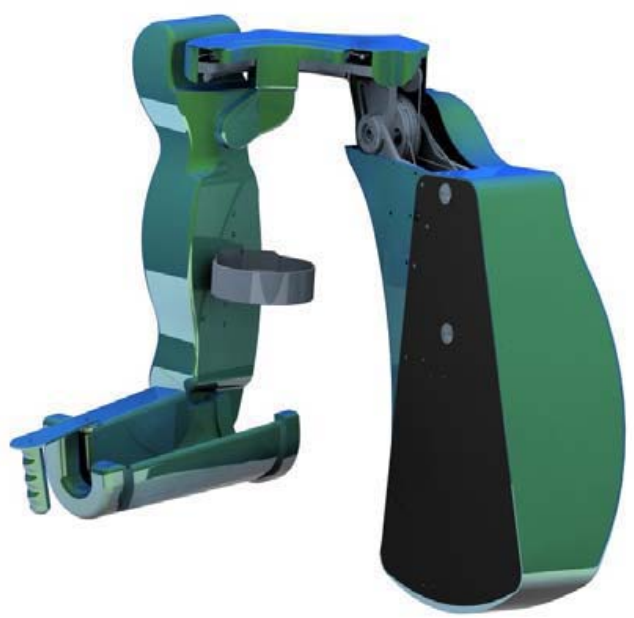

Fig 15. ABLE - 7 axis: an "artist" rendering of a planned version

\section{ACKNOWLEDGMENTS}

This work has been realized by the Interactive Robotics Unit of CEA-LIST. We would like to warmly thank the whole R\&D project team including our mechanical technicians, our students, doctorates and post-doctorates who have worked diligently to make ABLE this wonderful machine.

\section{REFERENCES}

[1] J.C. Perry, J. Rosen, S. Burns, “ Upper-Limb Powered Exoskeleton Design”, IEEE/ASME Transactions on Mechatronics, Volume 12, Issue 4, Aug. 2007 Page(s):408 - 417

[2] L. Frisoli, A. Borelli, Montagner, et al,“Arm rehabilitation with a robotic exoskeleleton in Virtual Reality", Proc. of IEEE ICORR 2007, Intern. Conf. on Rehabilitation Robotics

[3] Garrec P., Martins J.P., Gravez, Perrot Y., Measson Y., "A New Force-Feedback, Morphologically Inspired Portable Exoskeleton" Proceedings of 15th IEEE International Symposium on Robot and Human Interactive Communication (RO-MAN - 2006), September 2006, Hatfield, UK
[4] A. Gupta, M.K. O'Malley," Design of a haptic arm exoskeleton for training and rehabilitation", Mechatronics, IEEE/ASME Transactions on Volume 11, Issue 3, June 2006 Page(s):280 - 289

[5] P. Garrec, J.P. Martins, J.P. Friconneau, "A new Technology for Portable Exoskeletons", AMSE 2004 - Vol. 65 n 7/8, pp 13-22.

[6] P. Garrec, J.P. Friconneau, F. Louveau, “ Virtuose 6D: A new forcecontrol master arm using innovative ball-screw actuators", in Proceedings of ISIR 35th International Symposium in Robotics, Paris, March 2004

[7] J.M. Goubot, P. Garrec, "STeP: an innovative teleoperation system for decommissioning operations", Workshop "Decommissioning challenges: An industrial reality ?”, French Nuclear Energy Society, 23-28 November 2003, Avignon, France

[8] P. Garrec, "Systèmes mécaniques", in: Coiffet. P et Kheddar A., Téléopération et télérobotique, Ch 2., Hermes, Paris, France, 2002

[9] P. Garrec, French Patent: « Transmission à vis, écrou et câble attaché à la vis » for screw and nut transmission and cable - FR0101630, 2000 (EUR 01938347.0-2421 and US 10/296,740

[10] M. Bergamasco, B. Allotta, L. Bosio, L. Bosio, L. Ferretti, G. Parrini, G. M. Prisco, F. Salsedo, and G. Sartini," An arm exoskeleton system for teleoperation and virtual environments applications", in Proc. IEEE Int. Conf. Robot. Autom., vol. 2, 1994, pp. 1449-1454

[11] Mc Affee et al., USA Patent Number 9,193,963, "Force Reflecting Hand Controller", 1993

[12] J. Vertut, P. Coiffet, Téléopération « Evolution des techniques », vol. 3A, Hermes, Paris France, 1984

[13] G.-W. Köhler, Manipulator Type Book », Verlag Karl Thiemig, München, 1981

[14] J. Vertut, and al."Bilateral Servo Manipulator MA23 in Direct Mode and Via Optimized Computer Control" 2nd Remotely Manned Syst. Technol.Conf., 1975

[15] Galbiati et al., "A Compact Flexible Servo System for Master Slave Electric Manipulator”, 1964

[16] Goertz R. C. et al., "Master-Slave Servo-Manipulator" Model 2", Proc.4th Ann. Conf. Hot Lab. And Equip. 1, 1955 